\title{
Physical characteristics and reproductive performance in Aedes (Diptera: Culicidae)
}

\author{
H. Dieng, ${ }^{1}$ F. Abang, ${ }^{2}$ A.H. Ahmad, ${ }^{3}$ I. Abd Ghani, ${ }^{4}$ T. Satho, ${ }^{5}$ F. Miake, ${ }^{5}$ H. Ahmad, ${ }^{3}$ \\ W.F. Zuharah, ${ }^{3}$ A.H.A. Majid, ${ }^{3}$ R.E. Morales, ${ }^{6}$ N.P. Morales, ${ }^{7}$ C.N. Hipolito, ${ }^{3}$ G.T. Noweg ${ }^{1}$ \\ 1 Institute of Biodiversity and Environmental Conservation, University Malaysia Sarawak, Kuching, \\ Kota Samarahan, Malaysia; ${ }^{2}$ Faculty of Resource Science and Technology, University Malaysia \\ Sarawak, Kuching, Malaysia; ${ }^{3}$ School of Biological Sciences, University Sains Malaysia, Penang, \\ Malaysia; ${ }^{4}$ Faculty of Science and Technology, University Kebangsaan Malaysia, Kuala Lumpur, \\ Malaysia; ${ }^{5}$ Faculty of Pharmaceutical Sciences, Fukuoka University, Japan; ${ }^{6}$ Faculty of Tropical \\ Medicine, Mahidol University, Thailand; ${ }^{7}$ Faculty of Science, Mahidol University, Thailand
}

\begin{abstract}
Body size is a physical factor of crucial importance underlying important traits of the reproductive dynamics of both sexes in mosquitoes. Most studies on the influence of body size in mating success of dengue vectors addressed sperm transfer to females and did not con-
\end{abstract}

Correspondence: Hamady Dieng, Institute of Biodiversity and Environmental Conservation, Faculty of Resource Science and Technology, University Malaysia Sarawak, Kota Samarahan, Malaysia.

Tel.: +6010.3887158 .

E-mail: hamachan1@yahoo.com

Key words: Aedes aegypti; body size; mating success; fecundity.

Acknowledgements: we are thankful to the team of the Vector Control Unit of the School of Biological Sciences, University Sains Malaysia for providing eggs and larval food.

Contributions: HD, AHA, FB, IAG, TS, conceived and designed the experiments; HD, HA, WFZ, carried out the experiments; HD, HA, WFZ, AHAM, $\mathrm{CNH}$, analyzed the data; AHA, TS, HA, contributed reagents/materials/analysis tools; HD, TS, wrote the paper.

Funding: this research work was financed by a "Long Term Research Grant (LRGS) for Infectious Diseases, 2011 - 2014, Ministry of Higher Education, Malaysia" and USM (304/Pbiology/650575/U112).

Conflict of interest: the authors declare no potential conflict of interest.

Received for publication: 13 March 2016.

Revision received: 15 May 2016.

Accepted for publication: 16 May 2016.

(c) Copyright H. Dieng et al., 2016

Licensee PAGEPress, Italy

Journal of Entomological and Acarological Research 2016; $48: 5883$

doi:10.4081/jear.2016.5883

This article is distributed under the terms of the Creative Commons Attribution Noncommercial License (by-nc 4.0) which permits any noncommercial use, distribution, and reproduction in any medium, provided the original author(s) and source are credited. sider egg production, a prerequisite for population maintenance; male body size impact on reproduction has attracted little research interest with respect to sterile insect technique. In experiments involving differently sized adults, we examined whether the body size of the mates is a source of variation in reproductive outcome in Aedes aegypti. In the absence of male partners, large females (LF) showed better fecundity than small females (SF). In intraclass mating trials, egg production was much greater in largesized than smallsized pairs. There were comparable fecundities in large females mated with small males and

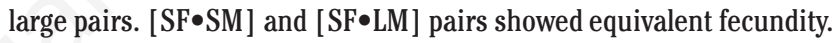
Nonmating did not result in the production of viable eggs by either small or large females. We also observed that eggs produced by largesized females mated with small males had better hatching success than those from either small or large pairs. Mating between small females and large males resulted in poor egg viability.

\section{Introduction}

Originating in Africa (Gubler, 2008), Aedes aegypti (Linnaeus) (Diptera: Culicidae) is now found in many urbanized areas worldwide (Womack, 1993). This mosquito species is a vector of three important viral diseases-yellow fever, chikungunya, dengue (Morrison et al., 2008) and Zika virus (Marcondes \& Ximenes, 2016). This latter disease causes more human morbidity and kills more people than any other mosquitoborne diseases globally (Farrar et al., 2007) and the World Health Organisation (WHO) rated dengue as the most important mosquitoborne viral disease in the world (WHO, 2013). No vaccines (Sabchareon et al., 2012) or specific therapeutic agents have yet been made available for dengue, and prevention is currently limited to vector control measures (WHO, 2014). Insecticide use - the main strategy to combat dengue vectors (WHO, 2010) - has been ineffectual due to the development of resistance (Whalon et al., 2008). Indeed, Ae. aegypti has developed resistance to nearly all insecticide classes (Dia et al., 2012).

There are several currently active fields of research to develop effective means of control of dengue vectors, i.e., the sterile insect technique (SIT), incompatible insect technique (IIT), and genetically modified mosquito (GMM) technologies (0'Connor et al., 2012; Bellini et al., 2007). The Food and Agriculture Organization (FAO/IAEA/USDA, 2003) reported that the triumph or failure of these control strategies is directly related to the ability of the released laboratory produced insects to effectively mate with their wild counterparts. For example, 
SIT has been used successfully to control a number of dipteran pests (Schetelig \& Handler, 2012; Ogaugwu et al., 2013). However, most of these programs were associated with reduced sexual competitiveness of the released insects (Oliva et al., 2012). Shelly and colleagues (2007) reported that the mass rearing inherent to SIT causes a reduction in the mating ability of the released individuals. The application of these technologies requires the rearing of substantial numbers of target insect larvae (Helinski et al., 2008; Alphey et al., 2010). However, larval competition is common in container-breeding mosquitoes (Reiskind et $a l ., 2009)$, and high larval density has been reported to have a negative effect on body size at emergence (Yoshioka et al., 2012). Under highly crowded conditions, larvae are exposed to increased competition for food (Muturi et al., 2011). Density-dependent competition for food during larval life is associated with a number of adult physical and physiological traits, including reduced feeding rate per individual, lower quantities of stored nutrients (Alto et al., 2008), and decreased adult size (Briegel, 2003).

In insects, size at emergence has a potentially crucial effect on important traits of reproductive biology in both sexes. Large-sized drosophilid males rarely fecundate smaller females (Partridge $e t$ al., 1987). In Ceratitis capitata (Wiedemann), the number of copulations, amount of sperm stored, and reproductive success are positively associated with female body size (Joachim-Bravo et al., 2009). Many reproductive traits in mosquitoes favor large-bodied adults. For example, a large body size is often associated with an increased number of mature oocytes (Briegel \& Timmermann, 2001), while small-bodied mosquitoes display delayed sperm cell development (Smith \& Hartberg, 1974), reduced sperm capacity (Renshaw et al., 1994), slow ovarian development, and low mating competitiveness (Ng'habi et al., 2005). In dengue vectors, large-sized males produce more sperm and experience less rapid seminal depletion than small males (Helinski \& Harrington, 2011). In addition, females are inseminated with more sperm by larger than smaller males (Ponlawat \& Harrington, 2009). Thus, the size of insect mates seems central to their mating capacity in nature and is presumably an important source of variation in mating ability and reproductive success. In support of this suggestion, it has been reported that large males often have better copulation and mating success in nature (Sawadogo et al., 2013).

In container-breeding mosquitoes, including dengue vectors, male and female larvae that pupate first are conceivably smaller than those that pupate later. In SIT, IIT, and GM, laboratory produced insects are released into the wild (Dobson, 2003), so they can mate with wild individuals of the target populations. Such populations are generally assemblages of males and females of different body sizes (Schneider $e t$ $a l ., 2004)$. This diversity in adults of different body sizes may affect the interactions between males and females of different sizes as well as variability in mating success. There have been some recent attempts to study male mating ability in dengue vectors (Oliva et al., 2012; Dieng et $a l ., 2013$ ), but these studies did not involve Ae. aegypti, a species that is currently the target of SIT and GMM operations in many parts of the world (Harris et al., 2012; Carvalho et al., 2014). Another recent study examined mating success in this species, taking into account body size (Ponlawat \& Harrington, 2009), but the authors did not focus on male size and reproductive outcome, i.e., egg production, a prerequisite for the production of subsequent generations and a determinant of population maintenance.

The present study was performed to examine whether body size affects the mating ability of Ae. aegypti and the reproductive outcomes of sexual cross-affinity between small- and large-bodied adults. In addition, we also investigated whether egg production and fertility of unmated females differ according to body size.

\section{Materials and methods}

\section{Mosquito colony}

The Ae. aegypti mosquitoes used in this study were derived from a colony established at the Vector Control and Research Unit (VCRU), University Sains Malaysia. Samples of eggs acquired from the Entomology Laboratory of VCRU were submerged in dechlorinated water. Larvae that hatched within 24 hours were raised in quintuplicate at a density of 100 - 150 per metallic enamel container (diameter=12 $\mathrm{cm}$, depth=2 cm) half-filled with dechlorinated water. They were supplied a mixture of dog biscuits, beef liver, yeast, and milk powder (2:1:1:1) according to the feeding regimen and procedures described previously ( $0.15 \mathrm{~g}$ on day 1 of development, $0.30 \mathrm{~g}$ on day 4 , with replacement of fresh water medium before the second feeding) (Dieng et al., 2014). Upon pupation, individuals were transferred into plastic cups (diameter $=7.6 \mathrm{~cm}$, depth $=5.2 \mathrm{~cm}$ ) the interior edge of which was lined with moist tissue paper. Pupal cups were placed in mosquito cages (cubic metallic wire covered with mesh net, $30 \times 30 \times 30 \mathrm{~cm}$; length $\times$ breadth $\times$ height). Upon emergence, adults were dispensed a $10 \%$ sucrose solution through cotton wicks. Three to five days after emergence, females were given blood meals from restrained mice placed inside cages for 30-60 minutes. Three days after blood meal uptake, females were given opportunities to oviposit in plastic cups with a capacity of $250 \mathrm{~mL}$, lined with a piece of filter paper as an oviposition substrate and half-filled with dechlorinated water. Eggs were allowed to dry under laboratory conditions (temperature $29^{\circ} \mathrm{C} \pm 3.0^{\circ} \mathrm{C}$, relative humidity $75 \% \pm 1 \% \mathrm{RH}$, and photoperiod $13 \mathrm{D}: 10 \mathrm{~L}, 1 \mathrm{~h}$ dusk). After three days of drying, eggs were stored in plastic desiccation vessels and used as egg banks.

\section{Production of body size cohorts}

Two populations of Ae. Aegypti - small and large adults - were then produced using the stored eggs and used for the experiments. To obtain two different size classes, two larval densities and two feeding regimens were used. The first group (Group 1), which consisted of 100 newly hatched larvae (L1) and the second group (Group 2) consisted of $200 \mathrm{~L} 1$. The larval feeding schedule and amounts of food supplied are shown in Table 1. Virgin experimental adults were obtained according to the procedures described elsewhere (Dieng et al., 2013). Pupae were placed individually into1.5-mL Eppendorf tubes containing $0.05 \mathrm{~mL}$ of dechlorinated water to separate males from females. Pupae were

Table 1. Amounts of food supplied to Aedes aegypti larvae nurtured at different numbers to obtain adults of two different size classes.

\begin{tabular}{|c|c|c|c|c|c|c|}
\hline \multirow{2}{*}{$\begin{array}{l}\text { Number of newly } \\
\text { hatched larvae (L1) }\end{array}$} & \multicolumn{6}{|c|}{ Food supply schedule and amounts } \\
\hline & Day 1 & Day 2 & Day 3 & Day 4 & Day 5 & Day 6 \\
\hline 100 (Group 1) & $3 \mathrm{~mL}$ of $0.15 \mathrm{~g}$ & No food given & $6 \mathrm{~mL}$ of $0.15 \mathrm{~g}$ & $0.3 g^{*}$ & $0.3 g^{*}$ & $0.3 \mathrm{~g}^{*}$ \\
\hline 200 (Group 2) & $3 \mathrm{~mL}$ of $0.15 \mathrm{~g}$ & No food given & $3 \mathrm{~mL}$ of $0.15 \mathrm{~g}$ & $0.1 \mathrm{~g}^{*}$ & $0.1 g^{*}$ & $0.1 \mathrm{~g}^{*}$ \\
\hline
\end{tabular}

Day 1: the first day of the occurrence of newly hatched larvae (L1) after eggs were submerged in water for 24 hours; Day 3: third day after the appearance of L1; Day 5: fifth day after the appearance of L1; Day 6: sixth day after the appearance of L1. *Supplied as powder. 
checked every day, and adults that emerged were sexed. All males from Group 1 were put together in a cage labeled LM; Group 1 females, Group 2 males, and Group 2 females were also placed in cages labeled LF, SM, and SF, respectively. Experimental mosquitoes were provided 10\% sucrose solution. Males and females from Group 1 were designated as large males (LM) and large females (LF), respectively, and those from Group 2 were designated as small males (SM) and small females (SF), respectively.

\section{Body size}

The wing lengths of adult specimens (16 males and 14 females) from Group 1 (LM and LF) and those of adults from Group 2 (10 SMs and $10 \mathrm{SFs}$ ) were measured as reported previously (Xue et al., 2010; Dieng et al., 2013). The length of one wing from each dead specimen was measured using a dissecting microscope (Olympus CX41; Olympus, Tokyo, Japan).

\section{Egg production and viability in non-mated females}

The first experiment examined fertility of eggs from unmated females of both sizes. Five virgin SFs (3-5 days old) were placed in a cage $(18 \times 18 \times 24 \mathrm{~cm}$; length $\times$ breadth $\times$ height $)$ and provided $10 \%$ sucrose solution. After one day of sugar feeding, females were provided with blood meals from a restrained white mouse for 30 minutes. The same treatment was performed for five virgin LFs. Three days after blood feeding, gravid females were placed in oviposition tubes. Laid eggs were permitted to dry for three days under laboratory conditions (temperature $29^{\circ} \mathrm{C} \pm 3.0^{\circ} \mathrm{C}$, relative humidity $75 \% \pm 1 \% \mathrm{RH}$, and photoperiod $13 \mathrm{D}: 10 \mathrm{~L}, 1 \mathrm{~h}$ dusk). Dried eggs were immersed in $20 \mathrm{~mL}$ of dechlorinated water.

\section{Fecundity of small and large females in intra-size class matings}

The fecundities of SF and LF mated with males from their own size class were investigated as follows. One SM (2-5 days old) and ten bloodfed SFs (3-5 days old) were placed in a cage with $10 \%$ sucrose solution. In addition, one LM (2-5 days old) and ten blood-fed LFs (3-5 days old) were placed in another cage and treated as above. Both the cage with $[\mathrm{SF} \bullet \mathrm{SM}]$ and the cage with $[\mathrm{LF} \bullet \mathrm{LM}]$ were quadruplicated. Three days after blood feeding, females were singly placed in oviposition tubes.

\section{Fecundity of small and large females in inter-size class matings}

The following experiment was performed to investigate the fecundity of LF when mated with SM. One SM (2-5 days old) and ten blood-fed LFs (3-5 days old) were allowed to cohabit in a cage with access to sucrose solution as described in the experiment on Fecundity of SFs and LFs in intra-size class matings. The number of replicates for the $[\mathrm{SF} \bullet \mathrm{LM}]$ cage was 4 . Egg production resulting from [LFs $\bullet$ LMs] in the experiment on Fecundity of SFs and LFs in intra size class matings served as a control. Three days after blood feeding, gravid females were placed in oviposition tubes. The numbers of eggs laid were recorded at the end of the oviposition period of 2 days. Four replicates of one LM (2-5 days old) and ten blood-fed SFs (3-5 days old) were caged, fed sucrose solution, and treated as described above. Here, the egg production resulting from [SFs $\bullet \mathrm{SMs}$ ] in Experiment 2 served as a control.

\section{Larval eclosion}

To examine whether the body sizes of adults in cross-mating pairs influence egg hatching success, samples of air-dried eggs from: i) 30 LFs cross-mated with one SM; ii) 34 LFs cross mated with one LM; iii) 20 SFs cross-mated with one LM; and iv) 15 SFs cross-mated with one
SM, were placed in 250-mL plastic vessels where they were flooded in $20 \mathrm{~mL}$ of hatching medium composed of $2 \mathrm{~mL}$ of dechlorinated water with $1 \mathrm{~mL}$ of larval food solution [0.003 $\mathrm{g}$ of mixture of dog biscuits, beef liver, yeast, and milk powder (2:1:1:1) in $100 \mathrm{~mL}$ of dechlorinated water]. All eggs were dried under the same conditions (temperature $29^{\circ} \mathrm{C} \pm 3.0^{\circ} \mathrm{C}$, relative humidity $75 \% \pm 1 \% \mathrm{RH}$, and photoperiod $13 \mathrm{D}: 10 \mathrm{~L}$, $1 \mathrm{~h}$ dusk). Hatching responses were monitored after a 24 -h flooding time. Flooding was repeated two more times with a 4-day drying period between two flooding sessions.

\section{Collection and analysis of data}

In the fertility and size class fecundity studies, the numbers of eggs laid were counted under an Olympus CX41 dissecting microscope at the end of the 3-day oviposition period. The mean values were used as measures of fecundity. In the larval eclosion study, the numbers of eggs that hatched were determined by enumerating the numbers of first-instar larvae after each of the three flooding events. These numbers were used to compute the egg hatching rates, used as an indicator of fertility, as the number of hatched eggs/total number of eggs $\times 100$. Wing length was used as an index of adult size, and was considered to be the distance in $\mathrm{mm}$ from the apical notch to the axillary margin, excluding the wing fringe, as reported previously (Xue et al., 2010). Statistical analyses were carried-out as described previously (Dieng et al., 2013). Briefly, the dissimilarities in fertility, fecundity, and egg hatching responses between the different crosses as well as differences in body size were examined by analysis of variance (ANOVA) using the Systat v.11 statistical software package (Systat Software Inc., 2004). In the egg hatching comparisons, the separation of means \pm SE was performed using Fisher's LSD (leastsignificant difference) test. In all analyses, $\mathrm{P}<0.05$ was taken to indicate statistical significance.

\section{Ethical considerations}

This study was carried out in accordance with the principles expressed in the Declaration of Helsinki. The study was approved by the Biological Research Ethics Committee at Universiti Sains Malaysia (USM).

\section{Results}

\section{Body size patterns}

The mean wing length of LMs was $1.96 \pm 0.14 \mathrm{~mm}$ and ranged between 1.28 and $2.54 \mathrm{~mm}$. SMs had a mean wing length of $1.12 \pm 0.02$ $\mathrm{mm}$ with a range of $0.98-1.22 \mathrm{~mm}$. There was a significant difference between the two male size (ANOVA: $\mathrm{F}=19.53$; $\mathrm{P}<0.001$ ). Mean wing length also differed significantly between $\mathrm{LFs}(2.29 \pm 0.15 \mathrm{~mm}$, range: $1.48-2.99 \mathrm{~mm})$ and SFs $(1.38 \pm 0.024 \mathrm{~mm}$, range: $1.25-1.48 \mathrm{~mm})$ (ANOVA: $\mathrm{F}=21.88 ; \mathrm{P}<0.001$ ), indicating that the former were larger than the latter (Figure 1).

\section{Egg production by differently sized unmated females and viability}

The mean number of eggs produced by unmated SFs was $29.60 \pm 6.23$ and ranged from 10 to 43 eggs. For the LFs, the mean egg production averaged $55.40 \pm 8.16$ eggs, with a range of 43 to 68 eggs. There was a significant difference in mean number of eggs produced between the two groups (ANOVA: $\mathrm{F}=10.64 ; \mathrm{P}=0.011$ ) (Figure 2). No eggs produced by unmated SFs or LFs hatched (Table 2). It was clear that the LFs had better fecundity than SFs, suggesting that larger females had greater larval-derived nutrient stores. 


\section{Egg production with intra-size class matings}

When LFs were mixed with a single LM, 64.7\% (34/40) of the females produced eggs. Egg production varied significantly between small and large pairs (ANOVA: $\mathrm{F}=14.34 ; \mathrm{P}<0.001$ ). For the large pair $([\mathrm{LF} \bullet \mathrm{LM}])$, the mean egg production was $54.52 \pm 4.85$ eggs and ranged between 8 and 117 eggs. When SFs were mixed with a single SM, $47.50 \%(19 / 40)$ of the females produced eggs. For the small pair $([\mathrm{SF} \bullet \mathrm{SM}])$, the mean number of eggs produced was $25.68 \pm 5.29$ and ranged between 1 and 73 eggs (Figure 3 ).

\section{Egg production with inter-size class matings}

When LFs were cohabited with one SM, 92.5\% (37/40) of the females produced eggs. Egg production from [LF•SM] $(58.21 \pm 5.17$ eggs, range: 8-100 eggs) tended to be slightly higher than that from [LF•LM] $(54.52 \pm 4.85$ eggs, range: 8-117 eggs). However, there was no significant difference between the two means (ANOVA: $\mathrm{F}=0.2$; $\mathrm{P}=0.605$ ) (Figure 4A). The mean egg production of SF mated with LM $([\mathrm{SF} \bullet \mathrm{LM}])$ was $28.20 \pm 5.91 \mathrm{eggs}$, and was similar to that of $[\mathrm{SF} \bullet \mathrm{SM}]$ (ANOVA: $\mathrm{F}=0.10 ; \mathrm{P}=0.754$ ) (Figure 4B).

\section{Comparison of fecundity in relation to mating status}

There was no significant difference in egg production between unmated and mated SFs (ANOVA: $\mathrm{F}=0.1 ; \mathrm{P}=0.707$ ) (Figure $5 \mathrm{~A}$ ) as well as between unmated and mated LFs (ANOVA: $\mathrm{F}=0.005 ; \mathrm{P}=0.947$ ) (Figure 5B).

\section{Egg hatching responses}

In the intra-class size mating involving large-sized adults, $67.6 \%$ (23/34) of females produced eggs that did not hatch. In contrast, all SFs mated with males of their own class size produced eggs that hatched. In the inter-class size mating, $40 \%$ (12/30) of LFs mated with SMs produced non-viable eggs, while $95 \%$ (19/20) of their small bodied counterparts mated with LMs produced eggs that did not hatch. Larval eclosion differed significantly between mating pairs (ANOVA: $\mathrm{F}=3.03$; $\mathrm{P}=0.033$ ). Egg hatching success gradually decreased when advancing from LF mated with SM (15.16\% $4.09 \%$; range: $0 \%-81.66 \%)$ to largesized pairs (5.161\% $1.88 \%$; range: $0 \%-38.18 \%)$ to SF mated with LM $(4.46 \pm 4.46$ eggs, range: $0 \%-89.36 \%)$ to small-sized pairs (1.96\% $1.96 \%$; range: $0 \%-29.41 \%)$. For both LFs and SFs, egg hatching tendency to be greater among eggs derived from crosses with heterosized males. The mean egg hatching success in LFs mated with SMs was significantly higher than those from [LF•LM] [Tukey HSD: Matrix of pairwise mean differences $(\mathrm{MPMD})=-9.99 ; \mathrm{P}=0.020],[\mathrm{SF} \bullet \mathrm{LM}]$ (Tukey HSD: MPMD $=-10.69 ; \mathrm{P}=0.030$ ) and $[\mathrm{SF} \bullet \mathrm{SM}$ ] (Tukey HSD: $\mathrm{MPMD}=-13.19 ; \mathrm{P}=0.015)$. No significant differences in egg hatching success were observed between $[\mathrm{LF} \bullet \mathrm{LM}]$ and SFs mated with LM (Tukey HSD: MPMD = $-0.69 ; \mathrm{P}=0.884$ ), and $[\mathrm{SF} \bullet \mathrm{SM}$ ] (Tukey HSD: $\mathrm{MPMD}=-3.20 ; \mathrm{P}=0.542$ ). More eggs hatched among those produced by SFs mated with LM that among those laid by the $[\mathrm{SF} \bullet \mathrm{SM}]$ pairs, but the difference was not statistically significant (Tukey HSD: MPMD $=-2.50$; $\mathrm{P}=0.664$ ) (Figure 6).

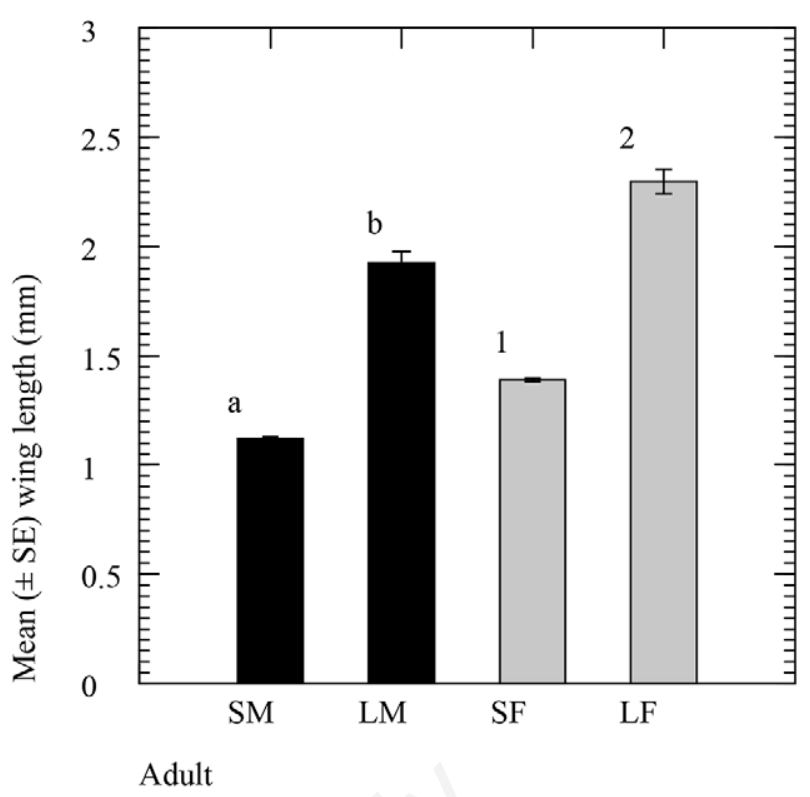

Figure 1. Mean wing length ( \pm standard error) of experimental small and large Aedes aegypti adults. Bars of similar color and with the same letter or number are not significantly different $(\mathrm{P}<0.05)$.

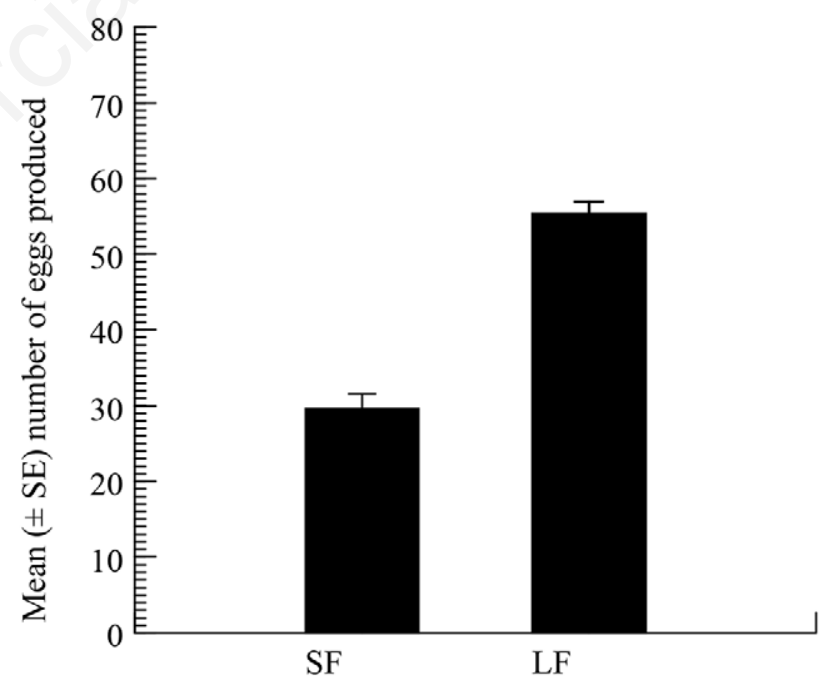

Female type

Figure 2. Numbers of eggs (mean \pm standard error) produced by unmated Aedes aegypti females.

Table 2. Hatching rates of Aedes aegypti eggs derived from unmated small and large females.

\begin{tabular}{lcc} 
Female type & Number eggs immersed & Hatching rate (\%) \\
Unmated small female & 148 & 0 \\
Unmated large female & 277 & 0 \\
\hline
\end{tabular}




\section{Discussion}

The major finding of the present study was that small-sized $A e$. aegypti can mate successfully with large-bodied partners, and that body size of the mates influenced reproductive success. Virgin SFs

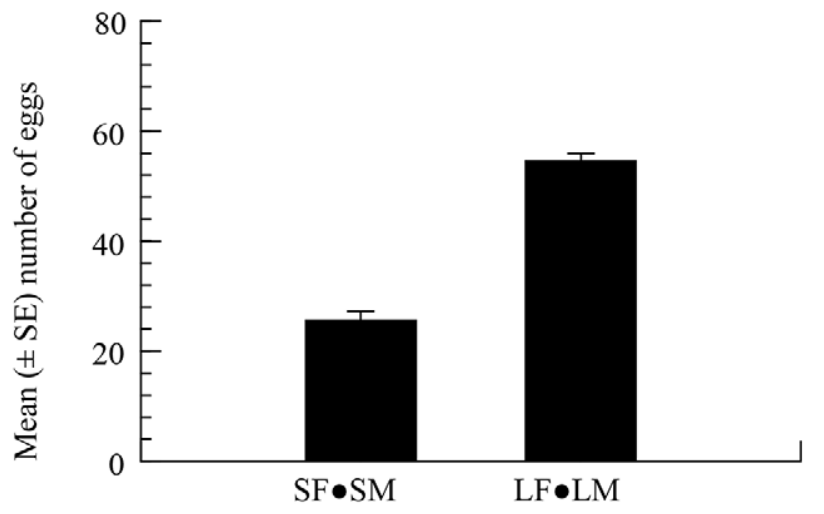

Figure 3. Numbers of eggs (mean \pm standard error) produced by small and large Aedes aegypti females (SFs and LFs, respectively) mated with corresponding males (SMs and LMs, respectively).

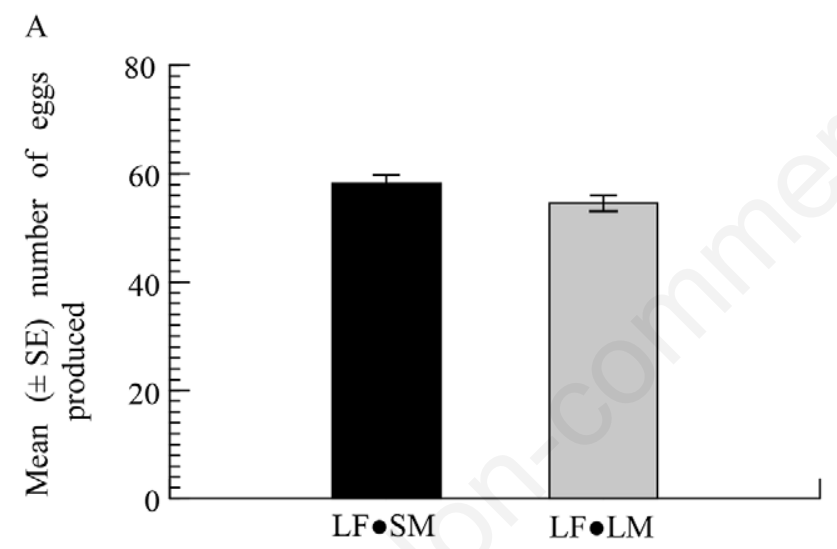

Cross type

$\mathrm{B}$

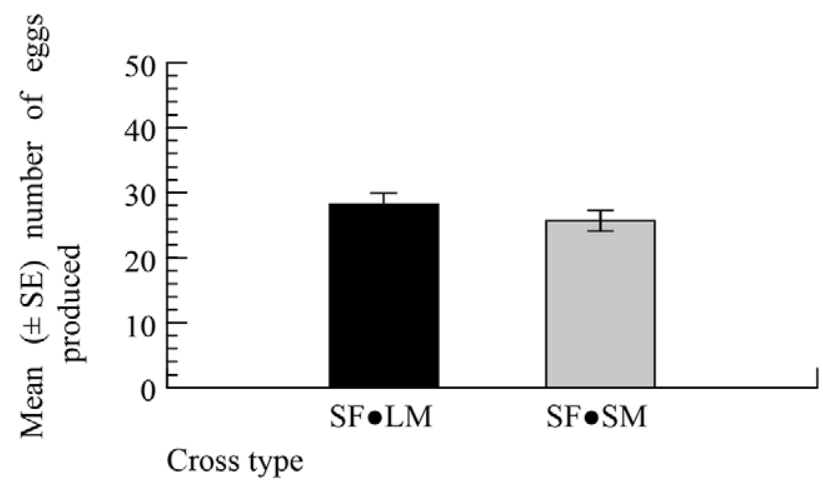

Figure 4. Numbers of eggs (mean \pm standard error) produced by LFs (A) of Aedes aegypti mated with SMs (A) and SFs (B) mated with LMs (B). cohabited with LMs produced viable eggs, as did LFs crossed with SMs. The degree to which these reproductive outcomes occurred exhibited size-dependent patterns in favor of large body size. Sugar- and bloodfed $A$ e. aegypti females developed eggs without ever mating with males. In mosquitoes, the female fat body undergoes structural modifications just after emergence, resulting in their fat tissues becoming

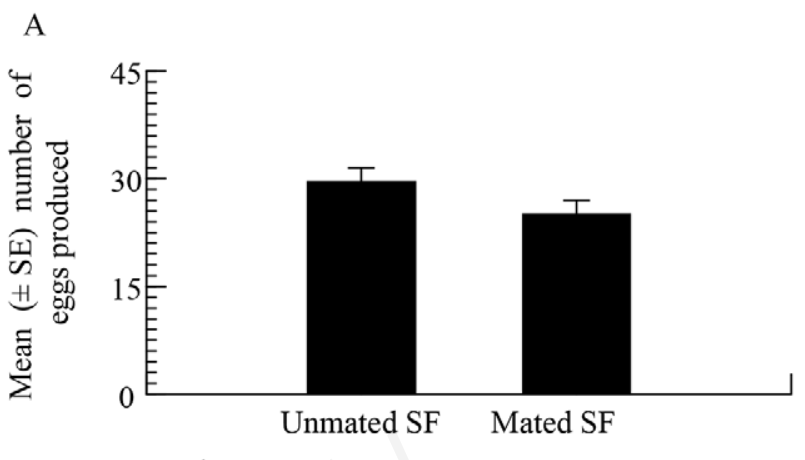

Mating status

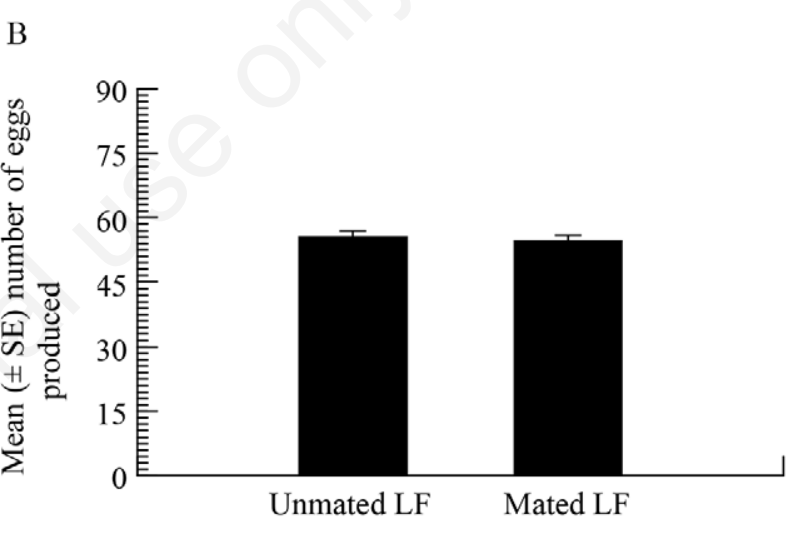

Mating status

Figure 5. Comparisons of egg production between mated and unmated SFs and LFs of Aedes aegypti.

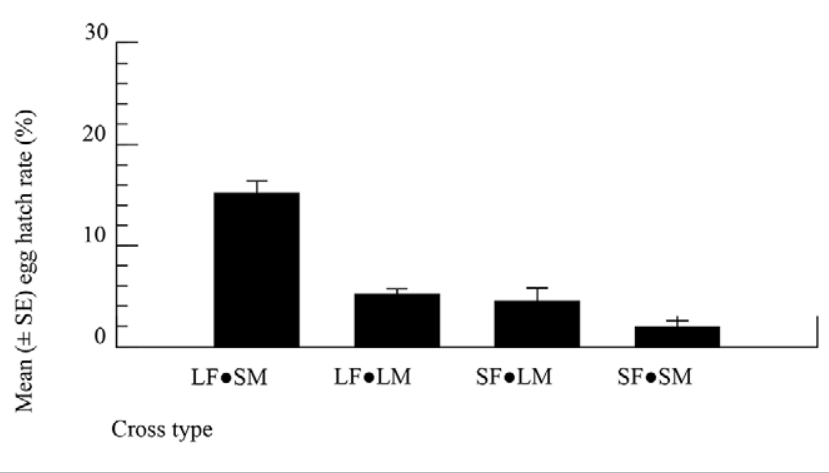

Figure 6. Mean ( \pm standard error) hatch rates of Aedes aegypti eggs from mating pairs involving different male and female size classes. 
responsive to vitellogenesis-inducing signals followed by a state of reproductive arrest (Attardo et al., 2009). In general, an anautogenous female mosquito must digest a blood meal to produce eggs (Zhou \& Miesfeld, 2009), and the ingestion of blood induces a series of events leading to egg production. Such an event cascade has been well documented in Ae. aegypti. Following blood meal uptake, the fat body is released from the state of reproductive arrest and thus initiates vitellogenesis (Baldini et al., 2013). The female utilizes blood-derived amino acids to synthesize yolk precursor proteins, which are discharged into the hemolymph (Attardo et al., 2009). Upon release, these proteins and their lipid transporters are incorporated into the ovaries (Cheon et al., 2001) to produce oocytes (Attardo et al., 2009). It is also widely believed that upon blood meal uptake, the brain of the female mosquito stimulates the ovaries to produce the steroid hormone ecdysone. In fact, the synthesis of 20-hydroxyecdysone (20E) breaks the state of reproductive arrest (Baldini et al., 2013) and activates the expression of yolk protein genes (Chen et al., 2005). That is why mosquito females that produce high levels of 20E themselves do not need to mate to complete egg development (Akst, 2013). As body dimensions are correlated with body size in Ae. aegypti (Timmermann \& Briegel, 1999), larger females are expected to have greater fat contents than small females. Therefore, it is likely that the LFs had higher levels of lipid tran sporter proteins, vitellogenin synthesis activities, and thus greater oocyte production capabilities than SFs. Note that in Aedes mosquitoes, both larval-acquired teneral reserves and a blood meal can act as sources of yolk precursors and stimuli for egg production (Briegel, 1990b). The maximum number of eggs is closely related to the number of ovarioles in ovaries, known to depend on larval nutriti onal history (Mori, 1979). As body size reflects larval nutrition, a large female that developed as a larva in an environment with an abundant nutritional food supply will have more ovarioles that a small female from a food-scarce habitat (Shelton, 1972). In addition, there is a close association between blood meal size and the timing of ovariole initiation to egg development. In Ae. aegypti adults with small blood meals, the yolk is resorbed from most oocytes, thus retarding yolk formation (Lea et al., 1978). In the present study, LFs and LMs were derived from well-nourished larvae, while SFs and SMs were from poorly fed larvae. Presumably, LFs had larger ovaries and consequently greater numbers of ovarioles than SFs. It is therefore likely that LMs had larger testes and thus greater sperm produ ction potential than SMs. In support of this suggestion, it has been reported that in some dipterans the sizes of the ovary (Botto-Mahan \& Medel, 2007) and testis (Pitnick, 1996) increase with body size. In mating experiments, we found that egg production varied considerably with body size of adults forming cross-mating pairs. Large-bodied females (LFs) produced far more eggs than their small-sized pe ers (SFs) when both mated with males of their respective sizes. The small-sized males and females (SMs and SFs) tested here were produced by rearing 200 newly hatched larvae with limited food supplies, whereas LMs and LFs were generated by raising 100 first instar larvae with an abundant food supply. Larvae maintained in a highly nutritious environment have more energy stores than those reared under crowded conditions with inadequate nutrition (Telang et al., 2007). All had similar sugar feeding opportunities.

Both SFs and LFs had the same blood feeding time (30 min) and only fully blood-fed females were assessed for egg production. Ae. aegypti has been reported to display size-dependent variation in hostsearching ability favoring larger individuals, which generally attack the host more than smaller individuals (Klowden, 1988). In this mosquito, the blood meal size threshold for egg development is high in smallsized females and low in larger females, and there is a close relationship between body size and blood meal mass (Xue et al., 1995). Indeed, a large-bodied female will tend to ingest more blood than a smaller female. Although we did not determine blood meal volumes or teneral reserves in the present study, the greater fecundity observed in LFs suggested that they had more yolk precursor sources than SFs.

Mating between $[\mathrm{LF} \bullet \mathrm{LM}]$ and $[\mathrm{LF} \bullet \mathrm{SM}]$ showed equivalent egg production, indicating comparable sperm transfer by both types of males. In nature, Ae. aegypti females exhibit polyandry, i.e., one female mates with many males (Helinski et al., 2012). This implies that a given female can receive sperm from one male, but will be receptive to additional inseminations. The males of dengue mosquitoes are known to be polygamous. A single Ae. aegypti male exposed to 20 females was shown to inseminate up eight of them within two days of cohabitation (Choochote et al., 2001). These authors also reported that one female of either Ae. aegypti or Ae. albopictus (Skuse) kept with 10 males can successfully mate with four and three males, respectively within $1 \mathrm{~h}$. They argued that repeated mating events with the same and/or different males occurred in the females of both species, and suggested that this multiple insemination behavior arose to ensure the transfer of adequate amounts of sperm to fertilize the eggs. Gwadz \& Craig (1970) reported that such phenomena result from copulation with semen depleted males. In general, small dipterans, including mosquitoes, have small testes, less energy to invest in testicular tissue growth, and transfer small amounts of sperm per copulation (Ponlawat \& Harrington, 2009). In the present study, SMs had a body size of $1.12 \pm 0.02$ $\mathrm{mm}$, whereas LF had an average body size of $2.29 \pm 0.15 \mathrm{~mm}$; and one male (2-4 days old) was caged with 10 LFs. With reference to these reports and the experimental design used, it is tempting to suggest that SMs and LFs acted analogously to the adults in the study of Choochote and co-workers (2001).

It has been reported that Ae. aegypti males pass 2000 sperm to a female, only half of which is retained in the spermatheca to produce about 85 eggs (Jones, 1968). However, ejaculate size adjustment is another plausible explanation for the similarity in egg production between the small pairs and $[\mathrm{SF} \bullet \mathrm{LM}]$. In many dipterans, males have been shown to gauge female quality (Martin \& Hosken, 2002; Lupold $e t$ al., 2011) based on a number of cues, including body size (Engqvist \& Sauer, 2003). For example, male fruit flies supply significantly more sperm to larger than smaller females. It is possible that the LMs in the present study tuned the amounts of sperm delivered to SFs taking into account their small body size and associated tiny spermatheca.

The presence of males showed a clear-cut effect on egg fertility of Ae. aegypti. The eggs produced by either unmated SFs or LFs did not hatch, whereas those laid by females kept with males hatched in considerable numbers, thus confirming that insemination is necessary for successful fertilization and production of viable eggs in this species. During copulation, an Ae. aegypti female receives sperm and seminal fluid holding proteins in the bursa copulatrix (Jones \& Wheeler, 1965), which are further stored in the spermatheca (Clements, 1999). Many studies have indicated a body size-associated effect on the amount of ejaculate transferred by a male to a female. For example, Ponlawat \& Harrington (2009) inves tigated the factors associated with Ae. aegypti male mating success, and found significantly more sperm release by large males than their small counterparts. In a related study, Ponlawat \& Harrington (2007) examined the impact of body size on sperm capacity in the same mosquito species and found this parameter to be a significant predictor of the total number of spermatozoa. They observed appreciably higher sperm counts in larger than small males. These discrepancies in sperm capacity could be explained by variations in the size of internal reproductive organs relative to body dimensions. In addressing this issue, Ponlawat and his colleague (2007) reasoned that, morphologically, body size is likely positively correlated with reproductive organ size. In drosophilids, testis size has been shown to increase with body size (Pitnick, 1996). In addition, ovary mass is heavier in larger than smaller females fruit flies (Botto-Mahan \& Medel, 2007). Gonad size is positively correlated with sperm production and transfer rates (Baker et al., 2003). The 
eggs laid by LFs crossed with SMs were highly fertile, but the hatching success rate of eggs from SFs mated with LMs was relatively low. Many parameters play a role in the hatching success of mosquito eggs. The post-oviposition moisture conditions and bacteria present in the environment, which affect the levels of dissolved oxygen in the medium in which eggs areimmersed, play central roles in hatchin g success (Borg \& Horsfall, 1953; Novak \& Shroyer, 1978). In the present study, all eggs were similarly preconditioned upon oviposition and the hatching medium used was identical in all egg hatch bioassays; therefore, it is unlikely that differences in egg hatching responses were due to discrepancies in egg preconditioning or immersion medium. Another parameter that may have impacted larval eclosion responses is the dormancy magnitude. All eggs tested remained immersed in the hatching medium for $24 \mathrm{~h}$. In Ae. aegypti, only some eggs hatch during the first flooding, while the others require dehydration and additional flooding (Gillet et al., 1977). The hatchability of dipteran eggs in relation to oocyte-sperm interactions has been determined in detail. Qazi \& co-workers (2003) reported that ovulation begins when sperm is being stored. This non-coordination of oocyte release with the release of sperm from storage has been reported to result in low fertilization efficiency of the first ovulated eggs (Chapman et al., 2001), which may explain the reduced hatchability of eggs from the $[S F \bullet L M]$ pairs. This has not yet been established in dengue mosquitoes and further investigations are required.

This s tudy was performed principally to determine the impact of body weight on reproductive success of the dengue vector Ae. aegypti with respect to potential implications for SIT and related genetic control approaches. The results of the present study indicated that reproductive outcome, and thus mating success, in Ae. aegypti is affected by the body sizes of the mating individuals-LFs mated with similarly sized males showed appreciably greater reproductive outcome than any other homologous or reciprocal crosses. Our study confirmed that small Ae. aegypti males can efficiently inseminate large-bodied females, which produce many eggs with appreciable levels of fertility. Ae. aegypti males are extremely sexually aggressive; a single female housed with 11 males received 50 copulation attempts by different males within 1 hour (Roth, 1948). This property may be especially pronounced in laboratory-reared males as they are acclimatized to living in small spaces. Such aggressiveness combined with their multiple mating behaviors in nature (Boyer et al., 2012) suggest a similar capacity to inseminate large numbers of females as observed in the boll weevil by Haynes and his colleague (1977).

\section{References}

AKST J., 2013 - Male mosquitoes trigger egg production. - The Scientist. Available from: http:/www.the-scientist.com/?articles.view/articleNo/ 38070/title/Male-Mosquitoes-Trigger-Egg-Production/

ALPHEY L., BENEDICT M.Q., BELLINI R., CLARK G.G., DAME D.A., SERVICE M.W., DOBSON S.L., 2010 - Sterile insect methods for control of mosquito-borne diseases: an analysis. - Vector-Borne Zoonotic Dis. 10: 295-311.

ATTARDO G.M., HANSEN I.A., RAIKHEL A.S., 2005 - Nutritional regulation of vitellogenesis in mosquitoes: implications for anautogeny. Insect Biochem. Mol. Biol 35: 661-675.

BAKER RH, DENNIFF M, FUTERMAN P., FOWLER K., POMIANKOWSKI A., CHAPMAN T., 2003 - Accessory gland size influences time to sexual maturity and mating frequency in the stalk-eyed fly, Cyrtodiopsis dalmanni. - Behav. Ecol. 14: 607-611.

BALDINI F., GABRIELI P., SOUTH A., VALIM C., MANCINI F., CATTERUCCIA F., 2013 - The interaction between a sexually transferred steroid hormone and a female protein regulates oogenesis in the malaria mosquito Anopheles gambiae. - PLOS Biol. 11: e1001695.

BELLINI R., CALVITTI M., MEDICI A., CARRIERI M., CELLI G.S.M., - 2007 - Use of the sterile insect technique against Aedes albopictus in Italy: first results of a pilot trial. - In: VREYSEN M.J.B., ROBINSON A.S., HENDRICHS J. (eds) Area-Wide Control of Insect Pests: From Research to Field Implementation. - Springer, Dordrecht: 505-515.

BRIEGEL H., 2003 - Physiological bases of mosquito ecology. - J. Vector Ecol. 28: 1-11.

BRIEGEL H., 1990b - Metabolic relationship between female body size, reserves, and fecundity of Aedes aegypti. - J. Insect Physiol. 36: 65-172.

BRIEGEL H., TIMMERMANN S.E., 2001 - Aedes albopictus (Diptera: Culicidae): physiological aspects of development and reproduction. - J. Med. Entomol. 38: 566-571.

BORG A., HORSFALL W.R., 1953 - Eggs of floodwater mosquitoes. II. Hatching stimulus. - Ann. Entomol. Soc. Am. 46: 472-478.

BOTTO-MAHAN C., MEDEL R., 2007 - What does determine gonad weight in the wild kissing bug Mepraia spinolai? - Mem. Inst. Oswaldo Cruz. 102: 233-235.

BOYER S, TOTY C, JACQUET M., LEMPÉRIÈRE G., FONTENILLE D., 2012 - Evidence of multiple inseminations in the field in Aedes albopictus. - PLoS One. 7: e42040.

CARVALHO D.O., NIMMO D., NAISH N., MCKEMEY A.R, GRAY P., WILKE A.B.B., MARRELLI M.T., VIRGINIO J.F., ALPHEY L., CAPURRO M.L., 2014 - Mass production of genetically modified Aedes aegypti for field releases in Brazil. - J. Visualized Exp. 83: e3579.

CATOR L.J., NG'HABI K.R., HOY R.R., HARRINGTON L.C., 2010 - Sizing up a mate: variation in production and response to acoustic signals in Anopheles gambiae. - Behav. Ecol. 21: 1033-1039.

CHAPMAN T., HERNDON L.A., HEIFETZ Y., PARTRIDGE L., WOLFNER M.F., 2001 - The Acp26Aa seminal fluid protein is a modulator of early egg-hatchability in Drosophila melanogaster. - Proc. Royal Soc. Lond. Ser. B: Biol. Sci. 268: 1647-1654.

CHEN L., ZHU J.S., SUN G.Q., RAIKHEL A.S., 2005 - The early gene Broad is involved in the ecdysterold hierarchy governing vitellogenesis of the mosquito Aedes aegypti. - J. Mol. Endocrinol. 34: 262-262.

CHEON HM, SEO SJ, SUN J., SAPPINGTON T.W., RAIKHEL A.S., 2001 Molecular characterization of the VLDL receptor homolog mediating binding of lipophorin in oocyte of the mosquito Aedes aegypti. Insect Biochem. Mol. Biol. 31: 753-760.

CHOOCHOTE W., TIPPAWANGKOSOL P., JITPAKDI A., SUKONTASON K.L., PITASAWAT B., SUKONTASON K., JARIYAPAN N., 2001 Polygamy: the possibly significant behavior of Aedes aegypti and Aedes albopictus in relation to the efficient transmission of dengue virus. - Southeast Asian J. Trop. Med. Pub. Health. 32: 745-748.

CLEMENTS A.N., 1999 - The Biology of Mosquitoes. Sensory Reception and Behavior, Vol. 2. - CAB International Publication, London.

DIA I, DIAGNE CT, BA Y., DIALLO D., KONATE L., DIALLO M., 2012 Insecticide susceptibility of Aedes aegypti populations from Senegal and Cape Verde Archipelago. - Parasit. Vectors. 5: 238.

Dieng H., Rajasaygar S., Ahmad A.H., Satho T., Miake F., Zuharah W.F., Fukumitsu Y., Saad A.R., Abdul Hamid S., Vargas R.E., Ab Majid A.H., Fadzly N., Abu Kassim N.F., Hashim N.A., Ghani I.A., Abang F.B., AbuBakar S., 2014 - Indirect effects of cigarette butt waste on the dengue vector Aedes aegypti (Diptera: Culicidae). - Acta Tropica 130C: 123-130.

Dieng H., Ruslan N.B., Ahmad A.H., Rawi C.S., Ahmad H., Satho T., Miake F., Zuharah WF., FuKumitsu Y., Saad A.R., Rajasaygar S., Vargas R.E., Majid A.H., Fadzly N., Ghani I.A., AbuBakar S., 2013 - Colonized Aedes albopictus and its sexual performance in the wild: implications for SIT technology and containment. - Parasit. Vectors 6: 206.

DOBSON S., 2003 - Reversing Wolbachia-based population replacement. Trends Parasitol. 19: 128-133.

ENGQVIST L., SAUER K.P., 2003 - Determinants of sperm transfer in the 
scorpionfly Panorpa cognata: male variation, female condition and copulation duration. - J. Evol. Biol. 16: 1196-1204.

Farrar J., Focks D., Gubler D., Barrera R., Guzmán M.G., Simmons C., Kalayanarooj S., Lum L., McCall P.J., Lloyd L., Horstick 0., DayalDrager R., Nathan M.B., Kroeger A., 2007 - Toward a global dengue research agenda. Trop. Med. Intl. Health. 12: 695-699.

Food and Agriculture Organization of the United Nations/International Atomic Energy Agency/United States Department of Agriculture, 2003 - Product quality control and shipping procedures for sterile mass-reared tephritid fruit flies. Manual, Version 5.0. IAEA, Vienna, Austria. Available from: http//www.iaea.org/programmes/nafa/d4/ index.html.

GILLET J.D., ROMAN E.A., PHILLIPS V., 1977- Erratic hatching in Aedes eggs: a new interpretation. - Proc. R. Soc. Lond. B 196: 223-232.

GUBLER D.J., 2008 - Dengue/Dengue haemorrhagic fever: history and current status, in new treatment strategies for dengue and other flaviviral diseases. In: BOCK G, GOODE J (eds) Novartis Foundation Symposium. John Wiley \& Sons Ltd.

GWADZ R.W., CRAIG G.B.JR., 1970 - Female polygamy due to inadequate semen transfer in Aedes aegypti. - Mosq. News. 30: 355-360.

Harris AF, McKemey AR, Nimmo D, Curtis Z., Black I., Morgan S.A., Oviedo M.N., Lacroix R., Naish N., Morrison N.I., Collado A., Stevenson J., Scaife S., Dafa'alla T., Fu G., Phillips C., Miles A., Raduan N., Kelly N., Beech C., Donnelly C.A., Petrie W.D., Alphey L., 2012 - Successful suppression of a field mosquito population by sustained release of engineered male mosquitoes. - Nat. Biotechnol. 30: 828-830.

HAYNES J.W., MITCHELL E.B., 1977 - Fractionated irradiation of boll weevils during pupal development: effect of sperm depletion and transfer as measured by female responsiveness. - J. Econ. Entomol. 70: 411-412.

HELINSKI M., HARRINGTON L.C., 2011 - Male mating history and body size influence female fecundity and survival in the dengue vector mosquito Aedes aegypti. - J. Med. Entomol. 48: 202-211.

HELINSKI M.E.H., HOOD R.C., KNOLS B.G.J., 2008 - A stable isotope dual-labelling approach to detect multiple insemination in un-irradiated and irradiated Anopheles arabiensis mosquitoes. - Parasit. Vectors. 1: 9 .

HELINSKI M.E.H., DEEWATTHANAWONG P., SIROT L.K., WOLFNER M.F., HARRINGTON L.C., 2012 - Duration and dose-dependency of female sexual receptivity responses to seminal fluid proteins in Aedes albopictus and Ae. aegypti mosquitoes. - J. Insect Physiol. 58: 1307-1313.

JOACHIM-BRAVO I.S., ANJOS C.S., COSTA A.M., 2009 - The role of protein in the sexual behaviour of males of Ceratitis capitata (Diptera: Tephritidae): mating success, copula duration and number of copulations. - Zool. 26: 407-412.

JOHANSSON A.S., 1964 - Feeding and nutrition in reproductive processes in insects. - Royal Entomol. Soc. Lond Symp. 2: 43-55.

JONES J.C., 1968 - The sexual life of a mosquito. - Scientific Am. 218: 108-115.

JONES J.C., WHEELER R.E., 1965 - An analytical study of coitus in Aedes aegypti (Linnaeus). - J. Morphol. 117: 401-424.

KLOWDEN M.J., BLACKMER J.L., CHAMBERS G.M., 1988 - Effects of larval nutrition on the host-seeking behavior of adult Aedes aegypti mosquitoes. - J. Am. Mosq. Contr. Assoc. 4: 73-75.

KLOWDEN M.J., CHAMBERS G.M., 1991 - Male accessory gland substances activate egg development in nutritionally stressed Aedes aegypti mosquitoes. - J. Insect Physiol. 37: 721-726.

LEA A.O., BRIEGEL H., LEA H.M., 1978 - Arrest, resorption or maturation of oocytes in Aedes aegypti: dependence upon the quality of the blood meal and the interval between blood meals. - Physiol. Entomol. 3: 309-316.

LUPOLD S, MANIER MK, ALA-HONKOLA 0., BELOTE J.M., PITNICK S., 2011 - Male Drosophila melanogaster adjust ejaculate size based on female mating status, fecundity, and age. - Behav. Ecol. 22: 184-191.

MARCONDES C.B, XIMENES M.D.F.F.D.M., 2016 - Zika virus in Brazil and the danger of infestation by Aedes (Stegomyia) mosquitoes. Rev. Soc. Bras. Med. Trop. 49(1): 4-10.

MARTIN 0.Y., HOSKEN D.J., 2002 - Strategic ejaculation in the common dung fly Sepsis cynipsea. - Anim. Behav. 63, 541-546.

MORI A., 1979 - Effects of larval density and nutrition on some immature and adults Aedes albopictus. - Trop. Med. 21: 85-103.

MORRISON A., ZIELINSKI-GUTIERREZ E., SCOTT T., ROSENBERG R., 2008 - Defining challenges and proposing solutions for control of the virus vector Aedes aegypti. - PLOS Med. 5: 362.

MUTURI E.J., KIM C.H., ALTO B.W., BERENBAUM M.R., SCHULER M.A., 2011 - Larval environmental stress alters Aedes aegypti competence for Sindbis virus. - Trop. Med. Intl. Health. 16: 955-964.

NG'HABI K, JOHN B, NKWENGULILA G., KNOLS B.G.M., KILLEEN G.F., FERGUSON H.M., 2005 - Effect of larval crowding on mating competitiveness of Anopheles gambiae mosquitoes. - Malaria J. 4: 49.

NOVAK R.J., SHROYER D.A., 1978 - Eggs of Aedes triseriatus and Ae. hendersoni: a method to stimulate optimal hatch. - Mosq. News. 38: 515-521.

O'CONNOR L., PLICHART C., SANG A.C., BRELSFOARD C.L., BOSSIN H.C., DOBSON S.L., 2012 - Open release of male mosquitoes infected with a Wolbachia biopesticide: field performance and infection containment. - PLOS Negl. Trop. Dis. 6: e1797.

OGAUGWU C.E., SCHETELIG M.F., WIMMER E.A., 2013 - Transgenic sexing system for Ceratitis capitata (Diptera: Tephritidae) based on female-specific embryonic lethality. - Insect Biochem. Mol. Biol. 43: 1-8.

OLIVA C.F., JACQUET M., GILLES J., LEMPERIERE G., MAQUART P.O., QUILICI S., SCHOONEMAN F., VREYSEN M.J., BOYER S., 2012 The sterile insect technique for controlling populations of Aedes albopictus (Diptera: Culicidae) on Reunion Island: mating vigour of sterilized males. - PLOS One. 7: e49414.

OLIVA C.F., DAMIENS D., VREYSEN M.J.B., LEMPERIÈRE G., GILLES J., 2013 - Reproductive strategies of Aedes albopictus (Diptera: Culicidae) and implications for the sterile insect technique. - PLOS One. 8: e78884.

PARTRIDGE L., EWING A., CHANDLER A., 1987 - Male size and mating success in Drosophila melanogaster: the roles of male and female behavior. - Anim. Behav. 35: 555-562.

PITNICK S., 1996 - Investment in testes and the cost of making long sperm in Drosophila. - Am. Nat. 148: 57-80.

PONLAWAT A., HARRINGTON L.C., 2007 - Age and body size influence male sperm capacity of the dengue vector, Aedes aegypti (Diptera: Culicidae). - J. Med. Entomol. 44: 422-426.

PONLAWAT A., HARRINGTON L.C., 2009 - Factors associated with male mating success of the dengue vector mosquito, Aedes aegypti. - Am. J. Trop. Med. Hyg. 80: 395-400.

QAZI M.C.B., HEIFETZ Y., WOLFNER M.F., 2003 - The developments between gametogenesis and fertilization: ovulation and female sperm storage in Drosophila melanogaster. - Dev. Biol. 256: 195-211.

REISKIND M.H., GREENE K.L., LOUNIBOS L.P., 2009 - Leaf species identity and combination affect performance and oviposition choice of two container mosquito species. - Ecol. Entomol. 34, 447-456.

RENSHAW M., SERVICE M.W., BIRLEY M.H., 1994 - Size variation and reproductive success in the mosquito Aedes cantans. - Med. Vet. Entomol. 8: 179-186.

ROBINSON A.S., FRANZ G., ATKINSON P.W., 2004 - Insect transgenesis and its potential role in agriculture and human health. Insect Biochem. Mol. Biol. 34: 113-120.

ROTH L.M., 1948 - A study of mosquitc behavior — an experimental laboratory study on the sexual behavior of Aedes aegypti (Linnaeus). - Am. Midland Nat. J. 40: 265-352.

Sabchareon A., Wallace D., Sirivichayakul C., Limkittikul K., 
Chanthavanich P., Suvannadabba S., Jiwariyavej V., Dulyachai W., Pengsaa K., Wartel T.A., Moureau A., Saville M., Bouckenooghe A., Viviani S., Tornieporth N.G., Lang J., 2012 - Protective efficacy of the recombinant, live-attenuated, CYD tetravalent dengue vaccine in Thai schoolchildren: a randomized, controlled phase $2 \mathrm{~b}$ trial. Lancet. 380: 1559-1567.

Sawadogo SP, Diabate A, Toe HK., Sanon A., Lefevre T., Baldet T, Gilles J., Simard F., Gibson G., Sinkins S., Dabiré R.K., 2013 - Effects of age and size on Anopheles gambiae s.s. male mosquito mating success. - J. Med. Entomol. 50: 285-293.

SCHETELIG M.F., HANDLER A.M., 2012 - A transgenic embryonic sexing system for Anastrepha suspensa (Diptera: Tephritidae). - Insect Biochem. Mol. Biol. 42: 790-795.

SCHNEIDER J.R., MORRISON A.C., ASTETE H., SCOTT T.W., WILSON M.L., 2004 - Adult size and distribution of Aedes aegypti (Diptera: Culicidae) associated with larval habitats in Iquitos, Peru. - J. Med. Entomol. 41: 634-642.

SHELLY T.E., MCINNIS D.O., RODD C., EDU J., PAHIO E., 2007 - Sterile insect technique and mediterranean fruit fly (Diptera: Tephritidae): assessing the utility of aromatherapy in a Hawaiian coffee field. - J. Econ. Entomol. 100: 273-282.

SHELTON R., 1972 - The effects of blood source and quantity on production of eggs by Culex salinarius Coquillet (Diptera: Culicidae). Mosq. News. 32: 31-37.

SMITH R.P., HARTBERG W.K., 1974 - Spermatogenesis in Aedes albopictus (Skuse). - Mosq. News. 34: 42-47.

STEINER L.F., MITCHELL W.C., HARRIS E.J., KOZUMA T.T., FUJIMOTO M.S., 1965 - Oriental fruit fly eradication by male annihilation. - J. Econ. Entomol. 58: 961-964.

SYSTAT V. 11 STATISTICAL SOFTWARE PACKAGE, 2004 - Systat for Windows: statistics. Systat Software Inc., Richmond.

TELANG A., FRAME L., BROWN M.R., 2007 - Larval feeding duration affects ecdysteroid levels and nutritional reserves regulating pupal commitment in the yellow fever mosquito Aedes aegypti (Diptera : Culicidae). - J. Exp. Biol. 210: 854-864.

TIMMERMANN S.E., BRIEGEL H., 1999 - Larval growth and biosynthesis of reserves in mosquitoes. - J. Insect Physiol. 45: 461-470.

WHALON M.E., MOTA-SANCHEZ D., HOLLINGWORTH R.M., 2008 Global Pesticide Resistance in Arthropods. - Oxford University Press, London.

WISHART G., RIORDAN C.F., 1959 - Flight responses to various sounds by adult males of Aedes aegypti. - Canadian Entomol. 23: 181-191.

WHO, 2010 - Dengue and severe dengue. - World Health Organization, Geneva. Avaialble from: http://www.who.int/mediacentre/factsheets/fs117/en/

WHO, 2013 - Global strategy for dengue prevention and control 20122020. - World Health Organization, Geneva. Avaialble from: http:/ apps.who.int/iris/bitstream/10665/75303/1/9789241504034 eng.pdf

WHO, 2014 - Dengue vaccine research. - World Health Organization, Geneva. Available from: http://www.who.int/immunization/ research/development/dengue_vaccines/en

WOMACK M., 1993 - The yellow fever mosquito, Aedes aegypti. Wing Beats. 5: 4.

XUE R.D., BARNARD D.R., SCHRECK C.E. 1995 - Influence of body size and age of Aedes albopictus on human host attack rates and the repellency of Deet. - J. Am. Mosq. Contr. Assoc. 11: 50-53.

XUE R.D., BARNARD D.R., MULLER G.C., 2010 - Effects of body size and nutritional regimen on survival in adult Aedes albopictus (Diptera: Culicidae). - J. Med. Entomol. 47: 778-782.

YOSHIOKA M., COURET J., KIM F., MCMILLAN J., BURKOT T.R., DOTSON E.M., KITRON U., VAZQUEZ-PROKOPEC G.M., 2012 - Diet and density dependent competition affect larval performance and oviposition site selection in the mosquito species Aedes albopictus (Diptera: Culicidae). - Parasit. Vectors 5: 225.

ZHOU G., MIESFELD R., 2009 - Differential utilization of blood meal amino acids in mosquitoes. - Open Access Insect Physiol. 1: 1-12. 